\title{
Novel HPLC Analysis of Hydrocortisone in Conventional and Controlled-Release Pharmaceutical Preparations
}

\author{
Ofosua Adi-Dako, ${ }^{1,2}$ Samuel Oppong Bekoe, ${ }^{3}$ Kwabena Ofori-Kwakye, ${ }^{1}$ \\ Enoch Appiah, ${ }^{3}$ and Paul Peprah ${ }^{3}$ \\ ${ }^{1}$ Department of Pharmaceutics, Faculty of Pharmacy and Pharmaceutical Sciences, Kwame Nkrumah University of \\ Science and Technology (KNUST), Kumasi, Ghana \\ ${ }^{2}$ Department of Pharmaceutics and Microbiology, School of Pharmacy, University of Ghana, Legon, Accra, Ghana \\ ${ }^{3}$ Department of Pharmaceutical Chemistry, Faculty of Pharmacy and Pharmaceutical Sciences, Kwame Nkrumah University of \\ Science and Technology (KNUST), Kumasi, Ghana
}

Correspondence should be addressed to Kwabena Ofori-Kwakye; koforikwakye@yahoo.com

Received 7 March 2017; Accepted 26 April 2017; Published 4 June 2017

Academic Editor: Nerea Ferreirós Bouzas

Copyright (c) 2017 Ofosua Adi-Dako et al. This is an open access article distributed under the Creative Commons Attribution License, which permits unrestricted use, distribution, and reproduction in any medium, provided the original work is properly cited.

\begin{abstract}
An isocratic sensitive and precise reverse phase high-performance liquid chromatography (RP-HPLC) method was developed and validated for the determination and quantification of hydrocortisone in controlled-release and conventional (tablets and injections) pharmaceutical preparations. Chromatographic separation was achieved on an ODS (C18), $5 \mu \mathrm{m}, 4.6 \times 150 \mathrm{~mm}$, with an isocratic elution using a freshly prepared mobile phase of composition methanol: water:acetic acid $(60: 30: 10, \mathrm{v} / \mathrm{v} / \mathrm{v})$ at a flow rate of $1.0 \mathrm{ml} / \mathrm{min}$. The detection of the drug was successfully achieved at a wavelength of $254 \mathrm{~nm}$. The retention time obtained for the drug was $2.26 \mathrm{~min}$. The proposed method produced linear detectable responses in the concentration range of 0.02 to $0.4 \mathrm{mg} / \mathrm{ml}$ of hydrocortisone. High recoveries of $98-101 \%$ were attained at concentration levels of $80 \%, 100 \%$, and $120 \%$. The intraday and interday precision (RSD) were $0.19-0.55 \%$ and $0.33-0.71 \%$, respectively. A comparison of hydrocortisone analyses data from the developed method and the official USP method showed no significant difference $(p>0.05)$ at a $95 \%$ confidence interval. The method was successfully applied to the determination and quantification of hydrocortisone in six controlled-release and fifteen conventional release pharmaceutical preparations.
\end{abstract}

\section{Introduction}

Hydrocortisone is a naturally occurring corticosteroid hormone secreted by the adrenal cortex and released during times of stress. The synthetic drug is employed in the management of inflammatory and rheumatoid diseases, allergic conditions, and autoimmune disorders such as Addison's disease (adrenal insufficiency disease). Hydrocortisone is commercially available in pharmaceutical formulations such as tablets, capsules, creams, ointments, and injections. Hydrocortisone may exist commercially as the unchanged hormone or as the acetate, cypionate, sodium phosphate, butyrate, valerate, and the sodium succinate forms [1].
A search of the literature revealed that few analytical methods such as ultraviolet spectrophotometry [2], electrokinetic capillary chromatography [3, 4], photochemically enhanced fluorescence [5], thin-layer chromatography(TLC-) densitometry $[1,6]$, and high-performance thin-layer chromatography (HPTLC) [7] have been used for the estimation of hydrocortisone in pharmaceutical formulations. However, modern chromatographic techniques such as highperformance liquid chromatography (HPLC) [8-12] and ultra-performance liquid chromatography (UPLC) [13] are preferentially employed for the determination of hydrocortisone in conventional pharmaceutical products such as tablets, creams, and injections. The different HPLC methods employ different chromatographic conditions including the use of 
complex and sometimes expensive solvent systems. Thus, access to some of these solvent systems in resource-poor countries in the developing countries can be challenging. The development of a simple and economical HPLC method using readily available reagents for the identification and quantification of hydrocortisone in pharmaceutical preparations would be an advantage in resource-poor countries.

The upsurge of autoimmune diseases such as adrenal insufficiency is a major health concern and the long-term use of conventional hydrocortisone tablets in the management of such a condition is problematic. The twice or thrice daily dosing of conventional hydrocortisone tablets to patients with adrenal insufficiency disease is incapable of mimicking the unique diurnal cortisol circadian pattern. Thus, most persons with adrenal insufficiency continue to suffer from poor therapeutic management resulting in poor quality of life and increased mortality. There is therefore the need for the development of creative and innovative treatment models for hydrocortisone replacement therapy in such dire situations. The use of controlled-release hydrocortisone oral dosage forms holds great promise with the capability to replicate the unique physiological pattern of hydrocortisone. In addition, such formulations are better able to manage and control the levels of morning androgen levels. The accurate monitoring of the quality of these promising new drug therapies is an important prerequisite to obtain quality healthcare [14]. The improved therapy will enhance patient compliance and ensure the delivery of controlled amounts of hydrocortisone at the absorption site compared to the immediate release pattern of conventional tablets [15].

The aim of this study was to develop and validate a simple, sensitive, and reproducible isocratic reverse phase HPLC method with ultraviolet/visible (UV) detection capable of determination and quantification of hydrocortisone in conventional and controlled-release pharmaceutical preparations. The application of the method in determining the content of hydrocortisone in controlled-release and commercially available conventional dosage forms was also studied.

\section{Materials and Methods}

2.1. Standards and Reagents. The reference material of hydrocortisone (Sigma Aldrich, USA), HPLC grade methanol (Fisher Scientific, UK), glacial acetic acid (Fluka, Germany), and water (double distilled) were used. All stock and working solutions were freshly prepared with distilled water for HPLC analyses.

2.2. Hydrocortisone Pharmaceutical Preparations. Fifteen commercially available hydrocortisone pharmaceutical preparations, comprising nine tablet and six injectable formulations, were sampled from retail pharmacies within the Kumasi and Accra Metropolitan areas of Ghana. Additionally, four controlled-release hydrocortisone tablet formulations, two controlled-release capsule formulations, and one conventional release hydrocortisone tablet formulation were obtained from the Department of Pharmaceutics and Microbiology, University of Ghana School of Pharmacy, Accra, Ghana.
2.3. Instrumentation and Optimized Chromatographic Conditions. A chromatograph comprising a P100 Spectra Series pump with a 785A Programmable Perkin Elmer UV/VIS absorbance detector was employed in the study. Isocratic mode of elution was employed. Chromatographic separation was successfully achieved on a JT Baker ${ }^{\circledR}$ ODS C18 column $(150 \times 4.60 \mathrm{~mm}$ ID, $5 \mu \mathrm{m}$ particle size $)$. Ultraviolet detection at a wavelength of $254 \mathrm{~nm}$ was able to ensure good resolution of peaks. The injection volume was $20 \mu \mathrm{L}$ and all analyses were undertaken at ambient temperature. A mobile phase consisting of methanol/water/acetic acid $(60: 30: 10 ; \mathrm{v} / \mathrm{v} / \mathrm{v})$ at a flow rate of $1.00 \mathrm{ml} / \mathrm{min}$ was employed. All chromatographic data were acquired using PowerChrom series 280 integrator software.

2.4. Preparation of Standard Solution. Fifty milligrams of hydrocortisone reference standard was accurately weighed and dissolved in $25 \mathrm{ml}$ of methanol as the diluent. The solution was transferred into a $50 \mathrm{ml}$ dry volumetric flask and was then sonicated for $5 \mathrm{~min}$. The volume was made up to the mark with methanol and mixed thoroughly $(1 \mathrm{mg} / \mathrm{ml}$ stock solution). A one in ten (1 in 10) dilution was made to obtain a working solution with concentration of $0.10 \mathrm{mg} / \mathrm{ml}$ of hydrocortisone. This solution with the required working concentration was then injected to determine the retention time of the analyte of interest using the developed method.

2.5. Analytical Method Validation. The new HPLC method was validated in terms of linearity, limits of detection and quantification, accuracy, precision (intraday and interday), specificity, robustness, and stability, in compliance with International Conference on Harmonization (ICH) guidelines [16].

2.5.1. Linearity. Serial dilutions were prepared from the stock solution of hydrocortisone reference standard $(1 \mathrm{mg} / \mathrm{ml})$ by pipetting $8.0 \mathrm{ml}, 4.0 \mathrm{ml}, 2.0 \mathrm{ml}, 1.6 \mathrm{ml}, 0.8 \mathrm{ml}$, and $0.4 \mathrm{ml}$ of the stock solution into separate $20 \mathrm{ml}$ volumetric flasks. The solutions were made up to volume with the diluent and mixed thoroughly. Solutions prepared were injected and analyzed using the developed method. The linearity of detector response was established by plotting a graph of concentration versus peak area of hydrocortisone standard and determining the correlation coefficient.

2.5.2. Limits of Detection and Quantification. The limit of detection (LOD) and limit of quantification (LOQ) of the new HPLC method were determined from the linear regression curve obtained from the linearity of hydrocortisone. The slope and standard deviations of the responses of the linear curve were used. The formulae for the calculation of the LOD and LOQ are given below:

$$
\begin{aligned}
\mathrm{LOD} & =\frac{3.3 \delta}{S} \\
\mathrm{LOQ} & =\frac{10 \delta}{S},
\end{aligned}
$$


where $\delta$ is standard deviation of the response; $S$ is slope of the calibration curve.

2.5.3. Accuracy. Into three separate $10 \mathrm{ml}$ volumetric flasks $1 \mathrm{ml}$ of a $1 \mathrm{mg} / \mathrm{ml}$ standard solution of hydrocortisone was pipetted. $0.8 \mathrm{ml}, 1.0 \mathrm{ml}$, and $1.2 \mathrm{ml}$ of formulated hydrocortisone solution $(0.1 \mathrm{mg} / \mathrm{ml})$ were added to the three volumetric flasks, respectively, to obtain concentrations at $80 \%, 100 \%$, and $120 \%$ levels. The solutions were analyzed using the developed method. Triplicate determinations were made for each solution and mean percentage recovery calculated.

2.5.4. Precision. Both intraday and interday precision of the HPLC method were assessed. For intraday precision, three solutions of different concentrations were prepared in separate $20 \mathrm{ml}$ volumetric flasks from the stock solution of hydrocortisone reference standard $(1 \mathrm{mg} / \mathrm{ml})$ by pipetting $8.0 \mathrm{ml}, 2.0 \mathrm{ml}$, and $0.4 \mathrm{ml}$ of the stock solution. Solutions were made up to volume with methanol. The various solutions where analyzed thrice during a particular day to obtain chromatograms from which recoveries and relative standard deviations (RSD) were calculated. For interday precision, a one in ten (1 in 10) dilution of the stock standard solution was prepared on three different occasions and analyzed. The solutions were analyzed on three consecutive days using the developed HPLC method to obtain chromatograms and the hydrocortisone content and relative standard deviation (RSD) were determined.

2.5.5. Specificity. The developed HPLC method was investigated for specificity to ensure there was no or minimal interference of analyte of interest from the solvent system. The mobile phase (blank) was analyzed, followed by an injection of a sample solution of hydrocortisone. After a ten-minute wash period, the blank was analyzed again.

2.5.6. Robustness. The robustness of the method was examined by introducing small changes in the composition of the mobile phase. Variation by $\pm 10 \%$ was done with respect to the methanol component of the mobile phase while keeping the composition of the others constant. Chromatograms obtained were analyzed using the RSD of the responses obtained.

2.5.7. Stability. The stability of solutions of hydrocortisone were studied over a period of 8 hours. Triplicate injections were made each hour and the chromatograms recorded.

2.6. Assay of Hydrocortisone Preparations. An amount of finely powdered hydrocortisone powder from each of the nine commercial conventional tablet formulations equivalent to $2.5 \mathrm{mg}$ hydrocortisone was individually weighed accurately and transferred to a $25 \mathrm{ml}$ volumetric flask containing $10 \mathrm{ml}$ of methanol. The solution was sonicated for $5 \mathrm{~min}$ and made up to volume with methanol. The resulting solution was then filtered using Whatman filter paper number 41 . The filtrate obtained was analyzed by making triplicate injections. The controlled-release hydrocortisone tablet and capsule formulations were analyzed in a similar way. In the analysis of the hydrocortisone injections, aliquots equivalent to $2.5 \mathrm{mg}$ hydrocortisone were pipetted from the six (6) injectable preparations into $25 \mathrm{ml}$ volumetric flasks and treated similarly to above. The peak areas of sample were determined and the amount of hydrocortisone was estimated from the linear regression calibration curves using the developed method. The official United States Pharmacopoeia method [11] was employed in analyzing the commercial samples. Statistical comparison between the official and developed methods was done using Student's $t$-test.

\section{Results and Discussion}

Controlled-release hydrocortisone preparations remain formulations of choice in the therapeutic management of adrenal insufficiency disease. This disease condition is a potentially life-threatening autoimmune disorder that requires prompt diagnosis and management to avoid fatality. The use of controlled-release formulations results in more stable cortisol concentrations during the diurnal cortisol circadian pattern than conventional hydrocortisone products [17]. It is however essential that suitable and accurate analytical methods are made available to assess the quality of the products with regard to their content. The development and validation of a simple isocratic RP-HPLC method for the determination of hydrocortisone in both conventional and controlled-release pharmaceutical formulations were the focus of this study. Review of literature indicates the employment of normal phase stationary support material $[18,19]$ and reverse phase stationary support material [20] for the development of HPLC method and further analyses of hydrocortisone products. There is yet no reported reverse phase HPLC with UV detection method capable of analyzing hydrocortisone in both conventional and controlled-release pharmaceutical formulations. The inclusion of acetic acid as a modifier in the mobile phase system ensured efficient resolution of hydrocortisone with minimal matrix effect from both conventional and controlled-release formulations. Readily available and cost effective solvents employed in the mobile phase ensured an efficient resolution and separation of hydrocortisone on a reverse phase column. Table 1 presents the optimized chromatographic conditions employed in the determination of hydrocortisone.

3.1. Analytical Method Validation. This method provides an option for the analyses of hydrocortisone in various salt forms compared to the individual methods available in some official compendia such as the United States Pharmacopoeia [11]. The analytical method being reported gave good linear detectable responses in the range of 0.02 to $0.4 \mathrm{mg} / \mathrm{ml}$ with coefficient of correlation $\left(r^{2}\right)$ of 0.9989 with well-resolved hydrocortisone and excipient peaks (Figures 1-4). The limit of detection and limit of quantification of $1.0662 \times 10^{-2} \mathrm{mg} / \mathrm{ml}$ and 3.23076 $\times 10^{-2} \mathrm{mg} / \mathrm{ml}$, respectively, obtained are an indication of the sensitivity of the method. The method showed good accuracy with good recoveries in the range of 98 to $101 \%$ recorded at three concentration levels of $80 \%, 100 \%$, and $120 \%$ (Table 2). The method was reproducible with good intraday 
TABLE 1: Optimized chromatographic conditions for the developed HPLC method.

\begin{tabular}{ll}
\hline Parameters & Optimized conditions \\
\hline Mobile phase & Methanol/water/acetic acid $(60: 30: 10, \mathrm{v} / \mathrm{v} / \mathrm{v})$ \\
HPLC column & JT Baker ODS C18,5 $\mu \mathrm{m}, 4.6 \times 150 \mathrm{~mm}$ \\
Flow rate & $1 \mathrm{ml} / \mathrm{min}$ \\
Wavelength detection & $254 \mathrm{~nm}$ \\
Diluent & Methanol \\
Injection volume & $20 \mu \mathrm{L}$ \\
\hline
\end{tabular}

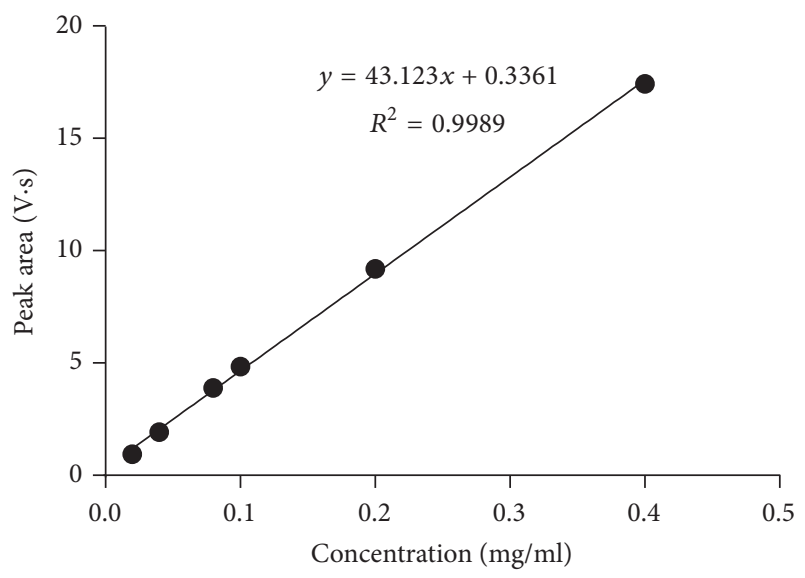

FIGURE 1: Calibration curve of hydrocortisone showing the linear detectable range $(0.02-0.4 \mathrm{mg} / \mathrm{ml})$.

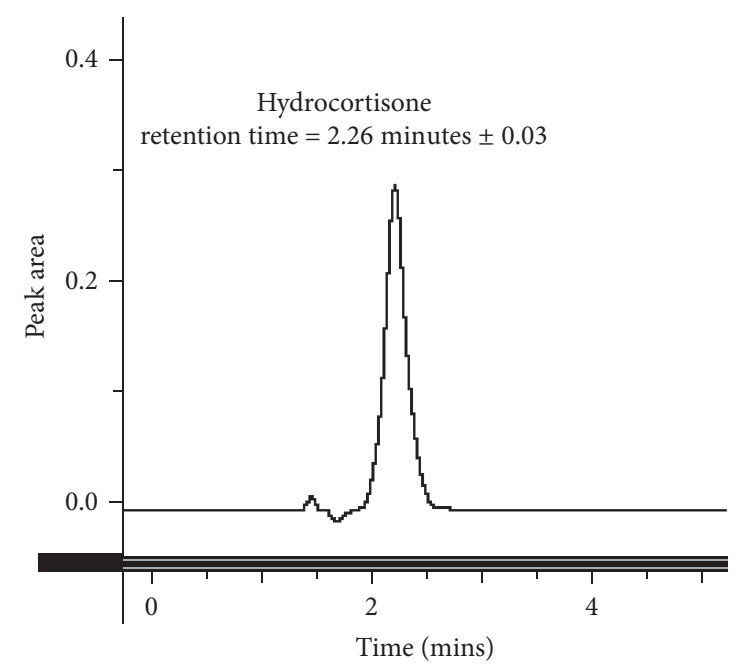

FIGURE 2: A chromatogram of hydrocortisone standard.

and interday precision of less than 1\% RSD (Tables 3 and 4). The new HPLC method showed high specificity and the robustness was less than $1 \%$ RSD (Tables 5 and 6). The method also demonstrated good stability over a period of $8 \mathrm{~h}(<6 \%$ RSD) (Table 7).

3.2. Application of Developed Method to the Analysis of Commercial Samples. Table 8 presents the characteristics, labelled

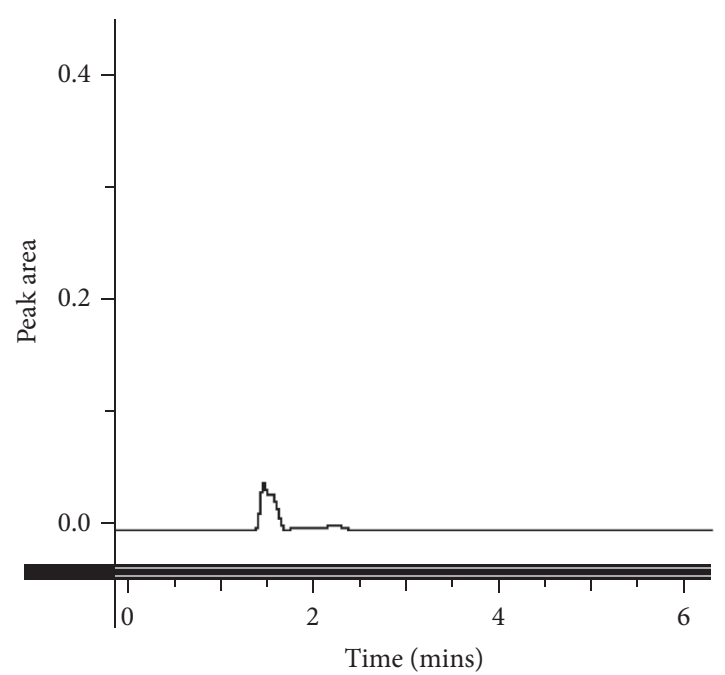

FIGURE 3: A chromatogram of an excipient in the hydrocortisone tablet.

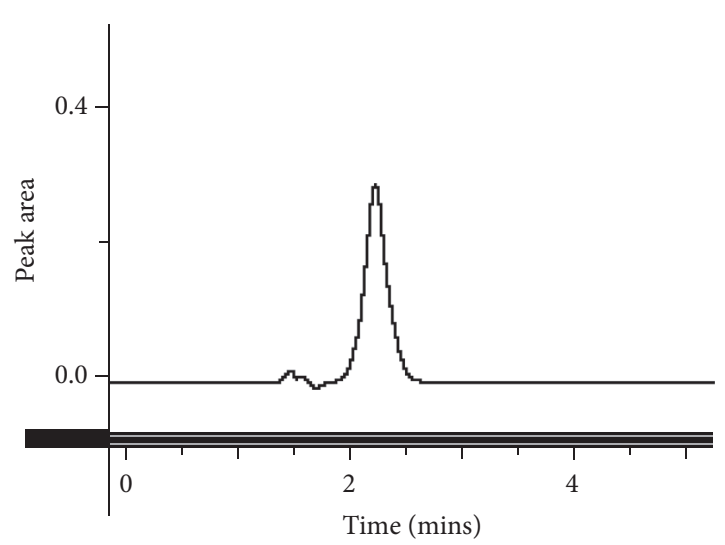

FIGURE 4: A chromatogram of the hydrocortisone tablet.

strength, and assay results of conventional hydrocortisone preparations which were analyzed using both the developed HPLC method and the official USP method. Statistical analysis ( $t$-test) of data from the two methods (official/USP and developed) showed no significant difference $(p>$ 0.05 ) at a $95 \%$ confidence interval (Table 9 ). The analytical method developed provides a relatively cheaper alternative technique for routine postmarket analyses of hydrocortisone formulations in resource-poor countries such as Ghana. The 
TABLE 2: Accuracy of the HPLC method showing the mean percentage recovery of hydrocortisone at three concentration levels.

\begin{tabular}{lcccc}
\hline Concentration levels & $\begin{array}{c}\text { Amount taken } \\
(\mathrm{mg} / \mathrm{ml})\end{array}$ & $\begin{array}{c}\text { Amount added } \\
(\mathrm{mg} / \mathrm{ml})\end{array}$ & Amount recovered & $\begin{array}{c}\text { Percentage recovery } \\
(\%)\end{array}$ \\
\hline \multirow{2}{*}{$80 \%$} & 0.10 & 0.08 & 0.07820 & 97.75 \\
& 0.10 & 0.08 & 0.07840 & 98.01 \\
& 0.10 & 0.08 & 0.07836 & 97.92 \\
$100 \%$ & 0.10 & 0.10 & 0.10073 & 100.73 \\
& 0.10 & 0.10 & 0.10120 & 101.20 \\
$120 \%$ & 0.10 & 0.10 & 0.10052 & 100.52 \\
& 0.10 & 0.12 & 0.11998 & 99.98 \\
& 0.10 & 0.12 & 0.12062 & 100.05 \\
\end{tabular}

TABLE 3: Intraday precision of proposed HPLC method showing the mean percentage recovery and RSD of hydrocortisone at different concentrations.

\begin{tabular}{lccc}
\hline $\begin{array}{l}\text { Number of } \\
\text { runs }\end{array}$ & $\begin{array}{c}\text { Concentration levels } \\
(\mathrm{mg} / \mathrm{ml})\end{array}$ & $\begin{array}{c}\text { Amount recovered } \\
(\mathrm{mg} / \mathrm{ml})\end{array}$ & $\begin{array}{c}\text { Percentage recovery } \\
(\%)\end{array}$ \\
\hline 1 & & 0.01990 & 99.52 \\
2 & 0.02 & 0.01997 & 99.83 \\
3 & & 0.01975 & 98.76 \\
1 & & 0.10052 & 100.52 \\
2 & 0.10 & 0.09945 & 99.45 \\
3 & & 0.10000 & 100.03 \\
1 & & 0.39952 & 99.88 \\
2 & 0.40 & 0.39828 & 99.57 \\
3 & & 0.39964 & 99.91 \\
\hline
\end{tabular}

${ }^{*}$ Mean of three replicate determinations.

TABLE 4: Interday precision of proposed HPLC method showing the mean percentage recovery and RSD of hydrocortisone on different days.

\begin{tabular}{lccc}
\hline Number of runs & \multicolumn{2}{c}{ Percentage recovery ${ }^{*}$ \%) } & Day 3 \\
\hline 1 & Day 1 & Day 2 & 98.52 \\
2 & 100.52 & 99.67 & 99.51 \\
3 & 99.45 & 98.36 & 99.72 \\
Mean & 100.03 & 98.85 & 99.80 \\
\% RSD & 100.00 & 0.71 & 0.33 \\
\hline
\end{tabular}

${ }^{*}$ Mean of three replicate determinations.

TABLE 5: Results of specificity studies of the proposed HPLC method.

\begin{tabular}{lc}
\hline Parameter & Response \\
\hline Mobile phase & No peak $(-)$ \\
Hydrocortisone & Single peak obtained \\
Mobile phase & No peak $(-)$ \\
\hline
\end{tabular}

(-): not detected.

validated method was also successfully applied to the analysis of six controlled-release hydrocortisone tablet and capsule formulations (Table 10). The application of the method in the analyses of tablets (conventional and controlled-release) and parenteral formulations indicated the versatility of the analytical procedure. The analyses of the hydrocortisone formulations yielded percentage hydrocortisone content of $95-104 \%, 96-103 \%$, and $87-103 \%$ for the four controlledrelease tablet formulations, two controlled-release capsule formulations, and fifteen conventional hydrocortisone formulations, respectively. All the controlled-release products were of good quality in terms of their content (percentage of content $\geq 90 \%$ ). The percentage of content of hydrocortisone powder was $100.44 \%$. Twelve products (all 6 injections, 6 tablets) out of the 15 commercial hydrocortisone products analyzed were determined to contain the right amounts of hydrocortisone as per United States Pharmacopoeia (USP) method and the developed HPLC method [11]. This study 
TABLE 6: Robustness of proposed HPLC method showing the mean percentage content of hydrocortisone when conditions were varied.

\begin{tabular}{lcc}
\hline Sample & $\begin{array}{c}\text { Original condition } \\
\text { \% content }\end{array}$ & $\begin{array}{c}\text { Varied condition } \\
\text { content }\end{array}$ \\
\hline 1 & 100.52 & 101.32 \\
2 & 100.75 & 100.65 \\
3 & 101.34 & 99.99 \\
Mean & 100.87 & 100.65 \\
\% RSD & 0.42 & 0.67 \\
\hline
\end{tabular}

TABLE 7: Stability of HPLC method showing the mean recoveries of hydrocortisone in solution over an eight-hour period.

\begin{tabular}{lcc}
\hline Time $(\mathrm{h})$ & Mean concentration & \% RSD \\
\hline 0 & 100.72 & 0.56 \\
2 & 100.29 & 0.63 \\
4 & 98.40 & 1.73 \\
6 & 95.82 & 3.54 \\
8 & 93.11 & 5.79 \\
\hline
\end{tabular}

TABLE 8: Characteristics and labelled strength of commercial hydrocortisone preparations analyzed using the developed HPLC method (DM) and the USP method.

\begin{tabular}{|c|c|c|c|c|c|c|c|c|}
\hline Code & $\begin{array}{l}\text { Dosage } \\
\text { form }^{*}\end{array}$ & Strength & $\begin{array}{l}\text { Country of } \\
\text { manufacture }\end{array}$ & $\begin{array}{l}\text { Batch } \\
\text { number }\end{array}$ & $\begin{array}{c}\text { Date of } \\
\text { manufacture }\end{array}$ & Expiry date & $\begin{array}{c}\text { Assay }^{* *} \\
(\%) \\
(\mathrm{DM})\end{array}$ & $\begin{array}{c}\text { Assay }^{* *} \\
(\%) \\
\text { (USP) }\end{array}$ \\
\hline HP1 & PFI & $100 \mathrm{mg}$ & Belgium & 14HB24 & $04 / 2014$ & $03 / 2017$ & 98.41 & 98.60 \\
\hline HP2 & PFI & $100 \mathrm{mg}$ & China & 131255 & $12 / 2013$ & $12 / 2016$ & 102.60 & 102.34 \\
\hline HP3 & PFI & $100 \mathrm{mg}$ & Belgium & 14HB52 & $12 / 2014$ & $11 / 2017$ & 100.64 & 100.42 \\
\hline HP4 & PFI & $100 \mathrm{mg}$ & India & $5 \mathrm{AB} 01007$ & $10 / 2015$ & $09 / 2018$ & 101.20 & 101.27 \\
\hline HP5 & PFI & $100 \mathrm{mg}$ & Belgium & $15 \mathrm{HB} 22$ & $09 / 2015$ & 08/2018 & 102.80 & 102.83 \\
\hline HP6 & PF1 & $100 \mathrm{mg}$ & India & 5AE04010 & $10 / 2015$ & $09 / 2018$ & 100.63 & 100.35 \\
\hline HT1 & Tablet & $10 \mathrm{mg}$ & China & 150801 & 08/2015 & 08/2018 & 86.80 & 86.45 \\
\hline HT2 & Tablet & $10 \mathrm{mg}$ & France & 5EH3C & $05 / 2015$ & $05 / 2018$ & 98.90 & 98.94 \\
\hline HT3 & Tablet & $5 \mathrm{mg}$ & France & 5ET4B & $04 / 2014$ & 04/2017 & 101.55 & 101.72 \\
\hline HT4 & Tablet & $10 \mathrm{mg}$ & India & KC004 & $02 / 2014$ & 02/2017 & 101.27 & 101.65 \\
\hline HT5 & Tablet & $5 \mathrm{mg}$ & India & KD157 & $04 / 2015$ & $04 / 2018$ & 87.69 & 87.36 \\
\hline HT6 & Tablet & $5 \mathrm{mg}$ & India & KD150 & $04 / 2015$ & $04 / 2018$ & 89.05 & 89.03 \\
\hline HT7 & Tablet & $10 \mathrm{mg}$ & $\begin{array}{l}\text { United } \\
\text { Kingdom }\end{array}$ & 13J11/C & $10 / 2013$ & $10 / 2016$ & 94.38 & 94.27 \\
\hline HT8 & Tablet & $10 \mathrm{mg}$ & $\begin{array}{l}\text { United } \\
\text { Kingdom }\end{array}$ & 13J14/B & $10 / 2013$ & $10 / 2016$ & 100.28 & 100.11 \\
\hline HT9 & Tablet & $10 \mathrm{mg}$ & $\begin{array}{l}\text { United } \\
\text { Kingdom }\end{array}$ & 13J12/A & $08 / 2013$ & $08 / 2016$ & 98.22 & 98.09 \\
\hline
\end{tabular}

${ }^{*} \mathrm{PFI}=$ powder for injection (im/iv). ${ }^{* *}$ Acceptance criterion $=90-110 \%$.

TABLE 9: Statistical comparison between the developed method and the USP method.

\begin{tabular}{ll}
\hline USP method (column B) versus developed method (column A) \\
\hline$t$-test \\
$p$ value & 0.9742 \\
$p$ value summary & Ns \\
Significantly different? $(p<0.05)$ & No \\
One- or two-tailed $p$ value? & Two-tailed \\
Mean \pm SEM of column A & $97.63 \pm 1.415 N=15$ \\
Mean \pm SEM of column B & $97.56 \pm 1.440 N=15$ \\
Difference between means & $-0.06600 \pm 2.019$ \\
95\% confidence interval & -4.202 to 4.070 \\
\hline
\end{tabular}

did not cover other pharmacopoeia specifications such as disintegration and dissolution tests.

\section{Conclusion}

It can be concluded that the developed and validated simple, isocratic, sensitive RP-HPLC method is useful for the determination and quantification of hydrocortisone in conventional and controlled-release pharmaceutical formulations. The method was successfully applied to commercial samples which indicate the ability of the analytical method to distinguish between good and poor quality hydrocortisone products. 
TABLE 10: Characteristics and labelled strength of pectin-based modified release hydrocortisone preparations analyzed using the developed HPLC method.

\begin{tabular}{lccc}
\hline Code & Dosage form & Strength & ${\text { Assay }(\%)^{*}}^{*}$ \\
HM1 & Tablet & $100 \mathrm{mg}$ & 103.36 \\
HM2 & Capsule & $100 \mathrm{mg}$ & 95.99 \\
HM3 & Capsule & $100 \mathrm{mg}$ & 103.29 \\
HM4 & Tablet & $100 \mathrm{mg}$ & 102.41 \\
HM5 & Tablet & $100 \mathrm{mg}$ & 104.38 \\
HM6 & Tablet & $100 \mathrm{mg}$ & 95.34 \\
\hline
\end{tabular}

${ }^{*}$ Acceptance criterion $=90-110 \%$.

\section{Conflicts of Interest}

The authors declare that there are no conflicts of interest regarding the publication of this paper.

\section{Acknowledgments}

The authors gratefully acknowledge the University of Ghana Office of Research, Innovation and Development (ORID) for providing a Faculty Development Grant to Ofosua AdiDako. They also appreciate the technical assistance provided by the technical staff of the Department of Pharmaceutical Chemistry, Faculty of Pharmacy and Pharmaceutical Sciences, KNUST, Kumasi, Ghana.

\section{References}

[1] A. Pyka, M. Babuska-Roczniak, and P. Bochenska, "Determination of hydrocortisone in pharmaceutical drug by TLC with densitometric detection in UV,' Journal of Liquid Chromatography and Related Technologies, vol. 34, no. 9, pp. 753-769, 2011.

[2] J. M. L. Gallego and J. P. Arroyo, "Spectrophotometric determination of hydrocortisone, nystatin and oxytetracycline in synthetic and pharmaceutical preparations based on various univariate and multivariate methods," Analytica Chimica Acta, vol. 460, pp. 85-97, 2002.

[3] J. M. L. Gallego and J. P. Arroyo, "Micellar electrokinetic capillary chromatography as an alternative method for determination of hydrocortisone and its most important associated compounds in local pharmaceutical preparations," Chromatographia, vol. 56, no. 6-7, pp. 455-462, 2002.

[4] J. M. L. Gallego and J. P. Arroyo, "Determination of hydrocortisone and associated compounds in pharmaceutical preparations by micellar electrokinetic chromatography," Journal of Liquid Chromatography, vol. 26, no. 7, pp. 1011-1025, 2003.

[5] C. E. Cardoso, R. O. R. Martins, C. A. S. Telles, and R. Q. Aucelio, "Sequential determination of hydrocortisone and epinephrine in pharmaceutical preparations via photochemically enhanced fluorescence," Microchimica Acta, vol. 146, no. 1, pp. 79-84, 2004.

[6] M. Dołowy, K. Kulpińska-Kucia, and A. Pyka, "Validation of a thin-layer chromatography for the determination of hydrocortisone acetate and lidocaine in a pharmaceutical preparation," The Scientific World Journal, vol. 2014, Article ID 107879, 10 pages, 2014.

[7] G. Genete, A. Hymete, and A. A. Bekhit, "Development and validation of HPTLC assay method for simultaneous quantification of hydrocortisone and clotrimazole in cream and applying for stability indicating test," Journal of the Chilean Chemical Society, vol. 57, no. 3, pp. 1199-1203, 2012.

[8] J. M. L. Gallego and J. P. Arroyo, "Comparison of HPLC and multivariate regression methods for hydrocortisone and lidocaine analysis of pharmaceutical preparations," Analytical and Bioanalytical Chemistry, vol. 374, no. 2, pp. 282-288, 2002.

[9] R. Hajkova, P. Solich, J. Dvorak, and J. Sicha, "Simultaneous determination of methylparaben, propylparaben, hydrocortisone acetate and its degradation products in a topical cream by RP-HPLC," Journal of Pharmaceutical and Biomedical Analysis, vol. 32, no. 4-5, pp. 921-927, 2003.

[10] B. Jancic-Stojanović, A. Malenović, S. Marković, D. Ivanović, and M. Medenica, "Optimization and validation of an RPHPLC method for analysis of hydrocortisone acetate and lidocaine in suppositories," Journal of AOAC International, vol. 93, no. 1, pp. 102-107, 2010.

[11] The United States Pharmacopoeia, Rockville, Md, USA, 2011.

[12] M. Pendela, G. Kahsay, I. Baekelandt, A. Van Schepdael, and E. Adams, "Simultaneous determination of lidocaine hydrochloride, hydrocortisone and nystatin in a pharmaceutical preparation by RP-LC," Journal of Pharmaceutical and Biomedical Analysis, vol. 56, no. 3, pp. 641-644, 2011.

[13] L. Nováková, L. Matysová, and P. Solich, "Advantages of application of UPLC in pharmaceutical analysis," Talanta, vol. 68, no. 3, pp. 908-918, 2006.

[14] S. Chan and M. Debono, "Replication of cortisol circadian rhythm: new advances in hydrocortisone replacement therapy," Therapeutic Advances in Endocrinology and Metabolism, vol. 1, no. 3, pp. 129-138, 2010.

[15] G. Johannsson, A. G. Nilsson, R. Bergthorsdottir, and etal., "Improved cortisol exposure-time profile and outcome in patients with adrenal insufficiency: a prospective randomized trial of a novel hydrocortisone dual-release formulation," Journal of Clinical Endocrinology and Metabolism, vol. 97, no. 2, pp. 473-481, 2012.

[16] in Proceedings of the International Conference on Harmonization specifications (ICH) Q2A, Validation of Analytical Procedures: Definitions and Terminology, Geneva, Switzerland, 1995, http:// www.ich.org/fileadmin/Public_Web_Site/ICH_Products/Guidelines/Quality/Q2_R1/Step4/Q2_R1_Guideline.pdf.

[17] E. Charmandari, N. C. Nicolaides, and G. P. Chrousos, "Adrenal insufficiency," The Lancet, vol. 383, no. 9935, pp. 2152-2167, 2014.

[18] M. J. Walters and W. E. Dunbar, "High-performance liquid chromatographic analysis of hydrocortisone drug substance, tablets, and enema," Journal of Pharmaceutical Sciences, vol. 71, no. 4, pp. 446-451, 1982.

[19] M. Alvinerie and P. L. Toutain, "Simultaneous determination of corticosterone, hydrocortisone, and dexamethasone in dog 
plasma using high performance liquid chromatography," Journal of Pharmaceutical Sciences, vol. 71, no. 7, pp. 816-818, 1982.

[20] R. D. Toothaker, W. A. Craig, and P. G. Welling, "Effect of dose size on the pharmacokinetics of oral hydrocortisone suspension," Journal of Pharmaceutical Sciences, vol. 71, no. 10, pp. 1182-1185, 1982. 

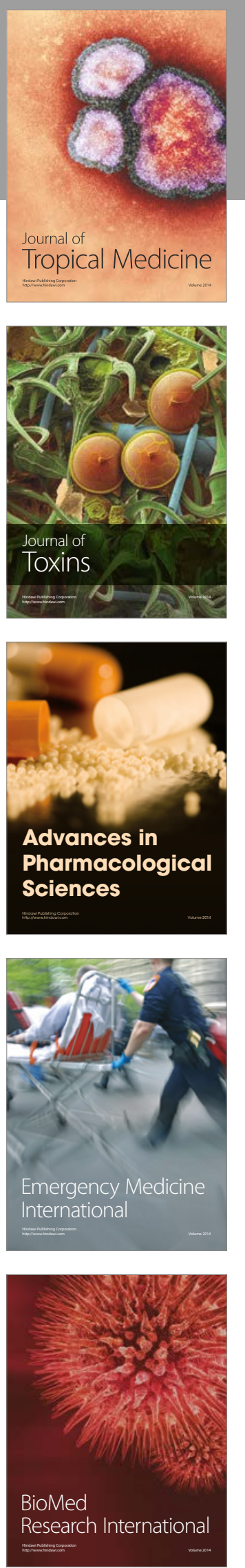
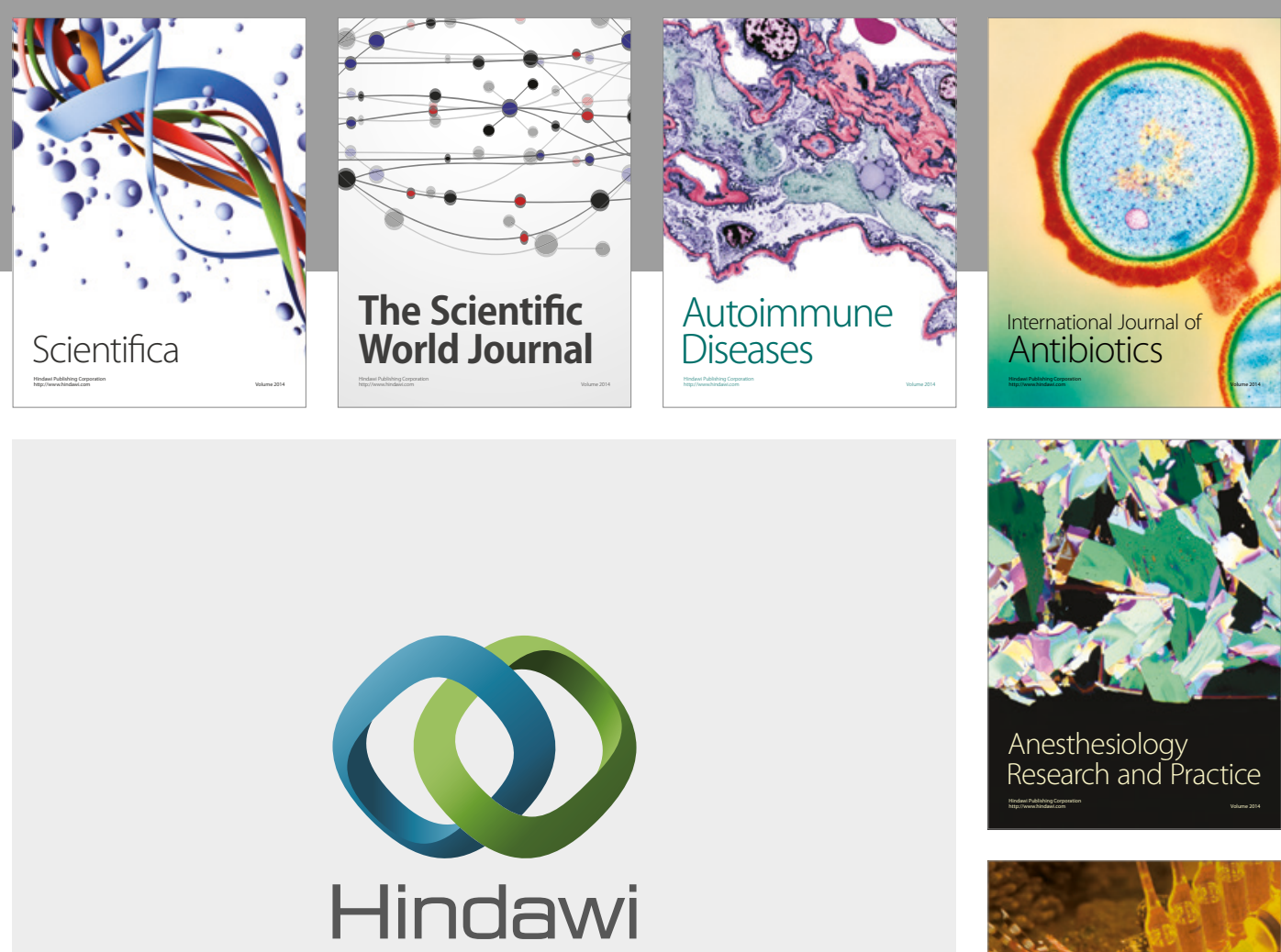

Submit your manuscripts at

https://www.hindawi.com
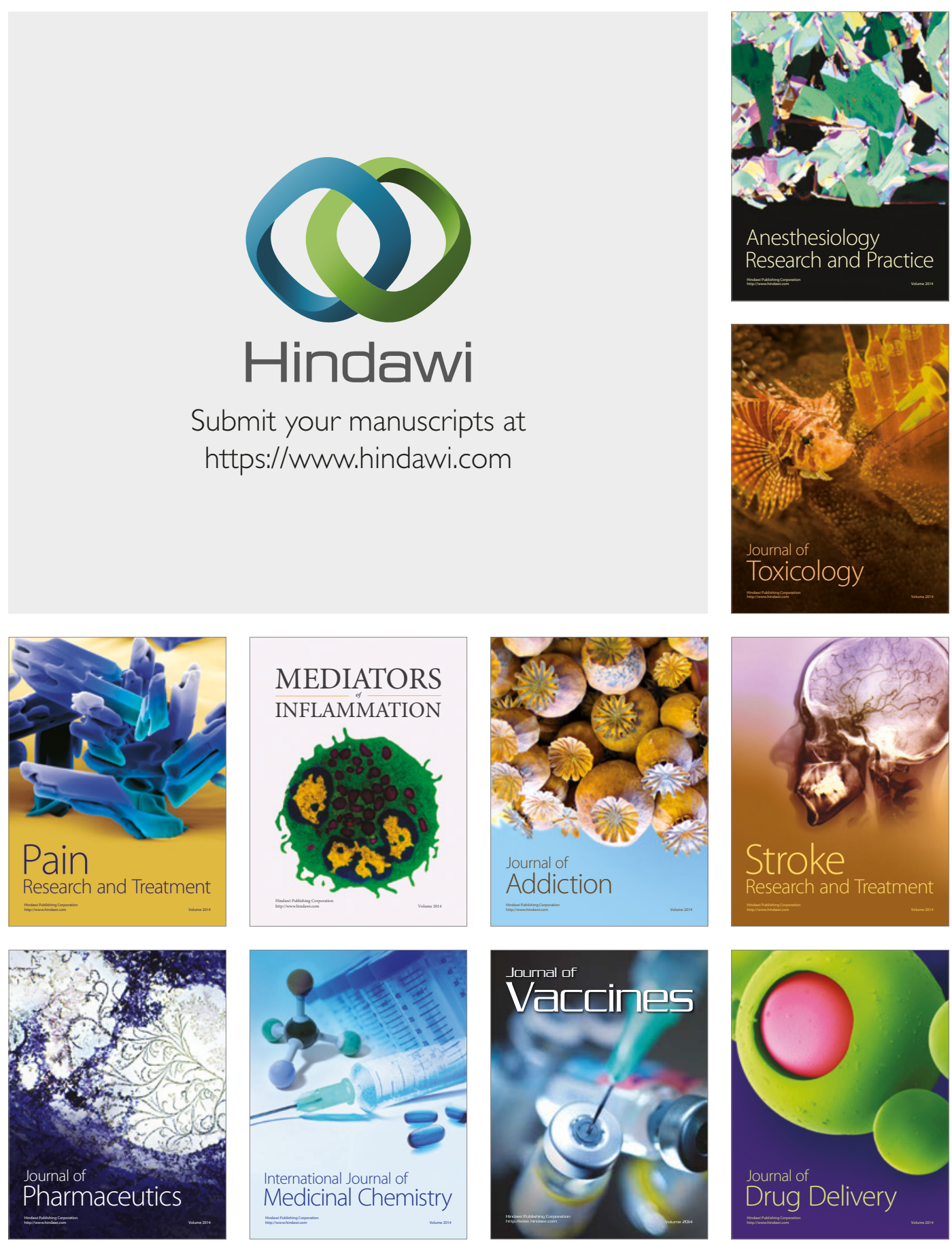